\title{
O DIREITO, A CIÊNCIA E A EDUCAÇÃO: RELAÇÕES INTERSISTÊMICAS
}

\author{
Leonel Severo Rocha ${ }^{1}$ \\ Giselle Marie Krepsky²
}

\section{Resumo}

Este artigo apresenta uma abordagem teórica sobre a necessidade de observação das relações sistêmicas entre o Direito, a Educação e a Ciência como possibilidade de superação da reprodução do conhecimento para que o sistema jurídico possa oferecer respostas mais adequadas aos direitos que surgem nesta sociedade complexa e globalizada. À luz da teoria pragmático-sistêmica de Niklas Luhmann e suas releituras contemporâneas, aponta limites e possibilidades de interferências intersistêmicas da Educação e da Ciência Jurídica no sistema do Direito, uma vez que todos são sistemas operacionalmente fechados, mas cognitivamente abertos. Conclui que, devido à autopoiese, não é possível a transposição direta da produção científico-jurídica nem tampouco do conhecimento produzido nas Universidades para o sistema do Direito, obstaculizando uma alteração significativa na estrutura deste. Todavia, indica que, alterações mais significativas para atender às novas demandas sociais, podem ser mais facilmente viabilizadas por meio da identificação de eventos comunicativos que possam provocar ruídos eficazes no Sistema do Direito.

Palavras-chave: Sistema Jurídico; Ciência e Educação; Relações intersistêmicas; Sociedade Complexa; (Re)produção do conhecimento.

\section{INTRODUÇÃO}

O escopo deste artigo é apresentar a necessidade de uma observação da relação entre três subsistemas parciais que compõem o sistema social: o Direito, a Ciência (Jurídica) e a Educação (Jurídica) para que se possa superar a reprodução do conhecimento e prospectar uma efetiva atenção aos novos direitos, à luz da matriz sistêmica. Nesta relação tríade, verifica-se que a preocupação com os fenômenos pertinentes ao objeto da Ciência Jurídica há tempos existe e tem alterado substancialmente o paradigma a partir do Estado Democrático de Direito. E que, tal qual já constatado a respeito da Educação Jurídica - até porque seguem imbricados - também sofre de crise paradigmática. Tal crise está relacionada com a complexa teia de relações possíveis no contexto

\footnotetext{
${ }^{1}$ Pós-doutorado em Sociologia do Direito pela Universita degli Studi di Lecce. Professor Titular da Universidade do Vale do Rio dos Sinos e Coordenador Executivo do Programa de Pós-Graduação em Direito (Mestrado e Doutorado, Capes 6). Professor do curso de Mestrado da Universidade Regional Integrada do Alto Uruguai (URI), estabelecendo Convênio PROCAD. Membro pesquisador do CNPq. E-mail: leonel.rocha@uol.com.br

${ }^{2}$ Doutoranda em Direito Público (UNISINOS). Professora Titular da FURB. Pesquisadora do Grupo de Pesquisas: Direitos Fundamentais, Cidadania e Novos Direitos (CNPQ). Professora titular do Curso de Direito da Universidade Regional de Blumenau (FURB), Blumenau, Santa Catarina, Brasil. E-mail: gkrepsky@outlook.com
} 
social. Quanto maior a possibilidade de relações diferenciadas em sociedade, maior é a necessidade de adequação de respostas do Direito.

É, portanto, a partir da constatação desta crise, e sob esse norte, que os subsistemas Ciência Jurídica e Educação Jurídica serão abordados tomando-se o Direito como sistema que, observado a partir da sociedade, tem a função de estabilizar as expectativas de comportamento e por meio do qual se vislumbra a satisfação dos novos direitos. E é sob uma visão pragmático-sistêmica que os novos direitos são considerados, ou seja, são mais do que a simples distinção entre velho direito/novo direito. São os contemplados com uma programação finalística em contraposição a uma programação condicional e em meio a uma codificação simples/complexo.

Se o Direito não tem conseguido atender às necessidades sociais emergentes a contento, se a Ciência Jurídica tem encontrado obstáculos epistemológicos para a melhor observação do Direito e se a Educação Jurídica tem se prestado eminentemente à reprodução do conhecimento e as pesquisas recentes que tratam destes problemas de maneira isolada não têm logrado muito êxito tanto do ponto de vista teórico quanto da práxis, o que se torna urgente é analisar tal problemática com a complexidade de interações de seus elementos constitutivos.

Para tanto, elege-se a Teoria dos Sistemas, a partir de Niklas Luhmann bem como a resignificação da teoria sistêmica realizada por Gunther Teubner como referencial teórico norteador da análise apresentada. Isto porque se faz necessária a compreensão do Direito, da Educação e da Ciência Jurídica como subsistemas que compõem o sistema social que é um "complexo de elementos em interação" (BERTALANFFFY, 2012, p. 84). Ambos constituem o ponto de partida para a compreensão do fenômeno, porquanto apresentam modelos teóricos que rompem com os tradicionais modelos da sociologia jurídica.

Partindo-se do conceito de sistema que Luhmann (2010, p. 91) define como "uma diferença que se produz constantemente, a partir de um único tipo de operação" e que "A operação realiza o fato de reproduzir a diferença sistema/meio, na medida em que produz comunicação somente mediante comunicação", verifica-se em sua teoria a concepção de sistema como sendo a comunicação e que só tem significado naquele sistema. Impende destacar por ora, que um sistema só existe enquanto possível a diferenciação de seu meio, e, portanto, não pode existir sem um ambiente. Para Luhmann (2010), os sistemas estão enclausurados em suas próprias operações e sendo assim, eles não podem conter estruturas, podem apenas, construí-las por meio de sua auto-organização. Por outro lado, a autopoiese significa exatamente o estado no qual se encontrará o sistema após a realização de suas operações internas, a partir das limitações impostas por ele mesmo. Tais conceitos são de suma importância para se estudar a reprodução e produção de conhecimento nos subsistemas sob comento.

Todavia, é na descrição deste mesmo processo que Teubner (2004) flexibiliza e gradua estes conceitos. Em que pese alguns conceitos da teoria dos sistemas terem sido reinterpretados por Teubner, ele deixa clara a possibilidade de influências entre subsistesmas sociais para que haja evolução dos regimes de produção normativa. 
De acordo com Corsi, Esposito e Baraldi (1996, p. 54, tradução nossa) o Sistema do Direito é um sistema funcional diferenciado, cuja função é manter estáveis as expectativas sociais. Essas expectativas são normas que permanecem estáveis independentemente de sua eventual violação. O Código que orienta o Direito está constituído pela diferença binária legal/ilegal, ou seja, existe comunicação jurídica toda vez que, em caso de controvérsia, alguém reivindica direitos e, em referência às normas vigentes, deve buscar decidir quem tem a razão da legalidade e quem não tem. O Sistema da Ciência, por sua vez, opera com base no meio de comunicação da verdade. $\mathrm{O}$ código a que a verdade se refere para produzir comunicações é a distinção entre o verdadeiro e o não verdadeiro: esses dois valores qualificam como científica qualquer comunicação observável com base neles. (CORSI, ESPOSITO e BARALDI, 1996, p. 38, tradução nossa).

A distinção entre os Sistemas do Direito e da Ciência esclarece-se sobre a distinção entre prestação e reflexão dos sistemas sociais. Luhmann (2007, p. 600, tradução nossa) considera "função a observação do sistema global, prestação a observação de outros sistemas e reflexão a observação do próprio sistema”. A partir desta distinção, "[...] a prestação da ciência, a partir da ótica do direito, é a investigação científica sobre o direito, [...] a reflexão do direito decorre fundamentalmente da doutrina jurídica, que estabelece os contornos da 'autodescrição' (sic) do sistema jurídico." (ZIMLER, 2002, p. 81-82). Ou seja, do ponto de vista da teoria sistêmica, a Ciência Jurídica é a observação científica sobre o que o Sistema do Direito auto-observa (sua teoria ou decisões).

No que se refere ao Sistema da Educação, sua função é induzir modificações nos sistemas psíquicos particulares, ou seja, através dele, possibilita-se que as pessoas (sistemas psíquicos) adquiram habilidades suficientes para se comunicarem na sociedade, exercendo seus papéis de acordo com diferentes profissões e em diferentes subsistemas sociais, porque uma das funções do Sistema da Educação também é formar para carreiras.

Assim, Corsi, Esposito e Baraldi (1996, p. 71, tradução nossa) esclarecem que a particularidade do Sistema Educativo está no fato de que ele não tem a função primária de elaborar uma comunicação como os demais sistemas. Ele não tem a função de comunicar, de efetivamente obter "êxito educativo", mas essencialmente de propiciar mudanças nos sistemas psíquicos da sociedade. Dessa forma, "el efecto de la educación, con otras palabras, se manifiesta fuera de la sociedad, precisamente en la capacidad y en la conciencia de los individuos, quienes deben tener la competencia de participar en la comunicación". (CORSI, ESPOSITO e BARALDI, 1996, p. 71, tradução nossa).

Desse modo, a função do Sistema da Educação é "não primária”, ou seja, é como uma função indireta de atuação nos demais sistemas, porque interfere nos sistemas psíquicos que vão circundar o meio e que vão assumir papéis em outros sistemas e neles participar da comunicação. Por conta dessa particularidade, a educação não tem um código próprio, embora tenha algo que se aproxime desse código que seria o estar apto ou não apto, hábil ou não hábil, mas, em tese, não tem código, já que não é possível codificar aquilo que é externo à sociedade. Assim, o 
que o Sistema da Educação possui são programas ao invés de códigos, os quais servem para propiciar o desenvolvimento de sistemas psíquicos.

Nesse contexto, apresenta-se uma breve revisão teórica a fim de elucidar objeto investigado à luz das produções científicas dos autores tomados como referência, bem como de interpretações mais recentes de novos pesquisadores.

\section{SOCIEDADE, COMPLEXIFICAÇÃO E NOVOS DIREITOS}

As categorias "sociedade complexa" ou "complexificação social" têm sido deveras utilizadas no meio acadêmico. No entanto, é preciso esclarecer que a categoria complexidade tem significado particular para a teoria dos sistemas. Para Luhmann (1983, p. 45):

[...] o mundo apresenta ao homem uma multiplicidade de possiveis experiências e ações, em contraposição ao seu limitado potencial em termos de percepção, assimilação de informação, e ação atual e consciente. Cada experiência concreta apresenta um conteúdo evidente que remete a outras possibilidades que são ao mesmo tempo complexas e contingentes. Com complexidade queremos dizer que sempre existem mais possibilidades do que se pode realizar.

Nesse sentido, Luhmann (2010, p. 184-185) esclarece que uma afirmação universal e genérica que se pode tecer sobre o sistema é a de que, entre ele e o meio circundante, há diferença e que se traduz em diferença de complexidade. Sendo assim, o meio no qual está inserido o sistema é sempre mais complexo do que este, posto que no meio existem muitas possibilidades relacionais e maior número de acontecimentos. Logo, essas possibilidades são muito maiores do que o sistema ou subsistema pode suportar ou processar em seu interior. Isso ocorre no plano das relações entre os elementos. E quando não é mais possível conectar-se com todos os elementos do sistema, a complexidade é dita de nível superior. Nesta, passa a haver uma seleção de quais elementos serão integrados ou assimilados pelo subsistema. Como em determinado tempo e circunstâncias as possibilidades de conexões relacionais e o número de elementos é absurdamente crescente, faz-se necessário que os sistemas ou subsistemas limitem estas possibilidades reduzindo a própria complexidade social. Para Luhmann (1998a, p. 16-17) ao se pensar em complexidade há que se ter em mente a situação da distinção entre elementos e relações. Isto porque, se um sistema possui cada vez mais um número maior de elementos, torna-se cada vez mais difícil a inter-relação destes elementos com outros. Assim, aumenta o número de novas inter-relações também. Sendo estas relações impossíveis de serem estabelecidas entre todos os elementos, há que se fazer uma escolha, impondo-se, assim, uma seleção. Por sua vez, essa seleção implica uma operação. Logo, as operações nesse cenário, também são complexas. Isso gera também um problema de observação, já que o conhecimento de um elemento não leva automaticamente ao conhecimento de todo o sistema. Há, assim, uma evidente falta de informação no sistema complexo, que já não pode mais ter certeza sobre suas escolhas ou seleções diante da 
incerteza do que o sistema observa. Dessa forma, a complexidade se torna tanto um problema para as operações, quanto para a observação que o sistema realiza.

Da mesma forma que existem muitas possibilidades relacionais, muitas também são as expectativas. Luhmann (1998b, p. 48) ressalta que: "Complejidad [...] significa coaccíon a seleccionar. Coaccíon a seleccionar significa contingencia, y contingencia significa riesgo". Portanto, o sistema há que realizar escolhas que geram riscos (contingência). Todavia, não há garantia de escolha certa ou decisão correta em meio a estas possibilidades inúmeras (dupla contingência). Rocha (2009, p. 21) ressalta que:

Há potencialmente muitas possibilidades diferentes de ser, e apenas uma possibilidade real de acontecer. Há um momento em que se poderia, portanto, escolher entre as possibilidades. Mas uma vez estando escolhida, esta constitui a realidade (as outras possibilidades continuam existindo como ambiente).

Sendo assim: "é necessário que se possa ter expectativas não só sobre o comportamento, mas sobre as próprias expectativas do outro" (SCHWARTZ, 2005, p. 76.) E é para a redução destas expectativas de expectativas que o subsistema social do Direito encontra sua função. Dessa forma:

O sistema jurídico aparece como um dos 'sistemas funcionais' do sistema social global, com a tarefa de reduzir a complexidade do ambiente, absorvendo a contingência do comportamento social, ao garantir certa congruência entre as expectativas de como os indivíduos vão se comportar, e a generalização dessas expectativas, pela imunização do perigo de decepcionarem-se. (GUERRA FILHO, 1997, p. 63).

Em meio a essa complexidade é que surgem várias outras expectativas sociais. É sabido que o progresso científico e o aumento do conhecimento trazem um aumento de expectativas. O Direito precisa adequar-se a esse contexto de múltiplos contextos, ou policontextos. Neste viés, Pereira e Simioni (2008, p. 234-235) asseveram que os novos direitos são aqueles em que a complexidade das operações fica evidente. Assim, na visão simplicidade/complexidade, os novos direitos referem-se ao que é complexo. É o que acaba por diferenciar também os programas finalísticos e os condicionais.

Nestes, a decisão jurídica ${ }^{3}$ não precisa preocupar-se com os riscos advindos dela, nem tampouco com as repercussões futuras. A decisão para esses direitos se torna simples, pois até mesmo as exceções às regras comportam condições de aplicabilidade de forma a reduzir a complexidade. Por outro lado, os programas finalísticos devem preocupar-se com o risco futuro do evento que envolve a decisão jurídica. Sendo voltado para o futuro, deixa de importar o que ocorreu e passa a ter relevância o que poderia ter ocorrido ou o que poderá ocorrer se se mantiverem as mesmas condições presentes. Portanto, são decisões de alta complexidade. Assim, colocando-

\footnotetext{
${ }^{3}$ Neste tocante, vale lembrar a classificação terminológica proposta por Silva (212, p. 50-51) que considera: "[...] decisão jurídica como distinção produzida pelo sistema mesmo, incontrolável por qualquer indivíduo ou coletividade, fruto da autopoiesis do sistema, da redundância de comunicação sobre o sentido de lícito e ilícito; decisão judicial como distinção produzida por juristas ou demais sistemas sociais, de forma que, por acoplamento estrutural, influenciem (ou não) a construção de sentido do direito da sociedade; decisão judiciária como distinções (interpretações e argumentações) produzidas exclusivamente pelos tribunais superiores.".
} 
se os novos direitos no lado da complexidade, os chamados velhos direitos ficam no lado "simplicidade". "O que fica excluído dos novos direitos é, portanto, a simplicidade dos velhos".

Nessas condições, a tautologia 'novos direitos são aqueles direitos que o direito mesmo diz serem novos' se desdobra na seguinte assimetria: 'Novos direitos são aqueles direitos que o direito mesmo diz serem novos pela complexidade envolvida nas suas operações'. E diz também: os velhos direitos são aqueles que continuam iguais, quer dizer, que reproduzem sua simplicidade. (PEREIRA; SIMIONI, 2008, p.235)

Contextualizado o sistema jurídico em meio à complexificação social, cumpre verificar o papel da Ciência e da Educação Jurídica.

\section{A CIÊNCIA, A EDUCAÇÃO E A TRANSFORMAÇÃO SOCIAL}

As expectativas da sociedade se alteram rapidamente com o aumento cada vez mais significativo de relações sociais, tornando a totalidade social cada vez mais complexa. Dessa forma, o atendimento destas expectativas recai sobre o sistema jurídico, ao qual fica incumbida a responsabilidade de satisfazer de forma estabilizante tais necessidades. Não é por outro motivo que, do sistema de justiça, tem se esperado respostas que atendam de forma satisfatória às demandas sociais.

Noutro viés, a superação paradigmática da própria Ciência Jurídica eivada pelas raízes positivistas possui suas próprias leis internas que a identificam e a diferenciam do ambiente social e que, por vezes, tem encontrado dificuldades de suplantar as barreiras epistemológicas a fim de tornar-se mais útil e eficaz nas respostas aos problemas jurídicos contemporâneos.

Completando este cenário, tem-se a Educação Jurídica, para a qual também tem sido delegada a responsabilidade de fornecer subsídios eficientes para que o Direito não seja um obstáculo à transformação social e na qual são depositadas esperanças de superação do status quo do próprio sistema jurídico. Afinal, os juristas (para não usar o termo: operadores do direito) são ao mesmo tempo egressos dela e reprodutores do conhecimento em suas funções. São, portanto, elementos que perpassam subsistemas diferenciados funcionalmente, mas que deles transferem informações igualmente circundantes.

Um mapeamento prévio demonstra que boa parte da produção científica atual tem se debruçado ora sobre os problemas eminentemente jurídicos como as adequações das decisões, a efetividade das garantias constitucionais, o aceso à justiça, entre outros e, muitas vezes, sobrecarregados de uma compreensão dogmática; ora sobre as falhas e limitações da educação jurídica, oferecendo sempre as mesmas soluções no campo dos currículos, formação de professores, educação para a humanidade, a cultura dos manuais, os métodos de ensino, a transformação da educação jurídica, e tantos outros diagnósticos que já soam repetitivos, mas são chancelados nos programas stricto sensu; ora no campo da ciência jurídica apontando a necessidade de reconfiguração do próprio objeto dela e dos métodos mais adequados para compreendê-la. 
Cada uma dessas produções de conhecimento parece estar envolta em uma reprodução constante, ainda que tenham explicado os fenômenos sob os mais diversos referenciais teóricos. Tais produções limitam o campo de observação e restringem os resultados em uma sistemática enclausurada nos seus próprios pressupostos e, com isso, caminham a poucos passos para uma compreensão mais próxima das reais expectativas da sociedade que não podem ser analisadas de forma fragmentada. Enfim, limitam o desenvolvimento e a diferenciação do Sistema da Ciência.

Se de um lado constata-se que as pesquisas contemporâneas sobre o ensino jurídico pouco êxito têm logrado enquanto possibilidade de mudança social, por outro, é necessário acreditar em caminhos factíveis para uma maior aproximação do "real" dessa forma de reprodução do conhecimento jurídico que é colaboradora da mantença do estado atual de crise. Assim, o que se vem destacando nos discursos teóricos, é que as formas de compreender a realidade pelos métodos tradicionais de pesquisa não permitiram uma melhor apreensão do fenômeno. A captura da realidade do fenômeno enquanto movimento constante, ambivalente e mediático é condição metodológica sem a qual não é possível prospectar objetivações mais apropriadas sobre a reprodução do saber jurídico de modo que se possam superar os paradigmas dantes comentados. Portanto, não só a insuficiência dos meios tradicionais de pesquisa deve ser superada, como é preciso encontrar um método mais apropriado de conhecer esta realidade.

Nesse sentido, Moraes (2009, p. 316) traz à baila uma constatação lancinante quando realiza uma denúncia e elabora uma crítica no que se refere ao conhecimento no campo da Educação e que se ajusta perfeitamente na perspectiva sob comento. Quanto à denúncia, a pesquisadora ressalta que o conhecimento e a própria ciência estão ameaçados e complementa com a crítica de que o momento "de ceticismo epistemológico e de relativismo ontológico que hoje nos cerca compromete acentuadamente a capacidade de as ciências superarem suas próprias antinomias no plano exploratório." (MORAES, 2009, p. 316). Não é possível contentarse com a própria reprodução teórica e doutrinária que tratam comumente sobre os problemas de métodos mais apropriados para o ensino do Direito, práticas pedagógicas emancipatórias, perfil do operador do Direito humanista, relações de ensino e aprendizagem, didáticas específicas, (entre outras categorias mapeadas), utilizando-as como referenciais representativos dos efetivos problemas sob pena de restringir as pesquisas a um realismo empírico ou apenas a cura para as consequências. O que parece indiscutível é que, qualquer matriz sob a qual se pretenda investigar ou analisar os fenômenos jurídicos, não pode estar distanciada das suas interlocuções diretas com a sociedade. Ora, se o Direito é subsistema social e sua estrutura é determinada pela comunicação (sociedade), o estudo sobre esta será determinante para o observador mais acurado. Nesse sentido Rocha (2005, p. 27) ressalta que:

[...] esta observação poderia estabelecer critérios para a constituição de uma teoria do direito, cuja função seria elaborar uma observação reflexiva sobre a totalidade da comunicação do 
direito. [...] Assim, para uma nova observação sobre o direito, capaz de permitir uma melhor compreensão das mudanças no entendimento do direito precisa-se trabalhar com matrizes teóricas diferentes daquelas tradicionais. [...] somente uma nova Matriz Jurídica, pode nos ajudar na reconstrução da teoria jurídica contemporânea.

De outra banda, é preciso considerar que, na área jurídica, a formação do profissional docente é reflexo da base epistemológica da própria Ciência do Direito e que, via de regra, ele exerce sua atividade profissional dentro do subsistema jurídico. Assim, é notável a instrumentalidade com a qual lida com os problemas. Esse modelo explica apenas em parte e, além disso, não justifica o atuar pedagógico do docente de Direito baseado preponderantemente no empirismo. A sociedade necessita de profissionais com habilidades muito além da aplicação das normas e se as aplicasse adequadamente já seria um ganho.

Nesse mesmo sentido Duran (2005, p. 203-204) ressalta que para cada necessidade existe meio apropriado de satisfazê-la e que: "para um novo Direito exige-se um novo profissional do Direito. E para o surgimento deste profissional, se faz necessário um novo modelo de formação”. Mas pergunta-se: as exigências da prática profissional citadas estão diretamente ligadas às necessidades sociais complexas globalizadas ou mais ao sistema burocrático jurídico que há tempos não vem logrando êxito na sua função? Se for possível partir do pressuposto de que essas práticas profissionais jurídicas estão muitas vezes distanciadas da necessidade social, por certo o engessamento do ensino jurídico também estará. Isso é percebido claramente nos currículos que há muito tempo estão centrados numa formação básica comum, seguida de disciplinas relativas às ciências aplicadas, à área profissionalizante, e essa origem reflete diretamente na formação do profissional jurídico e consequentemente do docente que atuará no Ensino Superior. Em meio a esta conjuntura é que se encontra a maioria dos docentes de Direito, quase sempre com a percepção positivista de que o que deve ser ensinado passa essencialmente pela técnica instrumentalista e raciocínio jurídico, e que o seu ensinar deve estar pautado tão somente no saber técnicocientífico em Direito. Aliás, questiona-se: que Direito? Não se preocupam se o modelo que reproduzem é pertinente do ponto de vista dos processos de ensinar e de aprender e mais, se efetivamente comportam conhecimentos que convirjam para uma efetiva evolução científica do Direito.

Esta forma de reprodução do conhecimento ou da Ciência Jurídica não está alienada do próprio sistema jurídico atual. Ora, como exigir do docente comportamento que se distancie da sua própria prática como profissional do Direito? Se o sistema jurídico lhe obstaculiza agir com mais liberdade, autonomia e criticidade na sua prática profissional, muito embora possa pensar desta forma, qual seria a motivação para que a base epistemológica do que se propõe a ensinar seja crítica, instigadora e questionadora do próprio agir? O mesmo é percebido da seguinte forma por Marques Neto (1982, p. 165, grifado):

Todas as concepções epistemológicas que ignoram o processo essencialmente constitutivo das ciências e de suas aplicações práticas, vendo no objeto de conhecimento um simples dado, transferem tal concepção para o ensino, o qual passa também a ser dado, imposto a uma pura aceitação, como se os seus pressupostos constituíssem verdades intocáveis e 
absolutas, acima de qualquer crítica. É assim que o dogmatismo dominante na ciência e na Filosofia do Direito vai servir de base ao dogmatismo do ensino jurídico, o qual por seu turno, retroalimenta e conserva o primeiro, num autêntico círculo vicioso, dentro de um sistema de pensamento extraordinariamente fechado.

Portanto, torna-se evidente a relação viciosa na qual se encontram o sistema jurídico, o profissional docente, o ensino jurídico e o egresso. Em que pese essa correlação ser reducionista, considerando a complexidade de variáveis envolvidas, ela explicita de forma direta quais complexos ou estruturas devem ser investigadas em constante inter-relação. Entretanto, a compreensão sobre o Sistema Jurídico que se toma como pressuposto para esta análise perpassa a simples e corriqueira utilização da categoria como sendo o sistema de justiça e o conjunto normativo. Ressalta-se então, que são as complexificações das inter-relações entre os subsistemas no eterno devir e suas implicações na reprodução do conhecimento posto na e para a manutenção do status quo que devem ser compreendidas mediante um olhar crítico e revelador do fenômeno do Ensino do Direito.

As pesquisas e estudos no campo educacional (Stricto sensu) que sucederam estes problemas evidenciam que a busca por métodos e currículos ideais para o ensino do Direito e a necessidade de formação de docentes profissionais nesta área são, sem sombra de dúvidas, os objetos principais de investigação até então. Muitas constatam, mesmo que apenas no campo teórico, o ciclo vicioso sob comento, e até mesmo no campo experimental sugerem novos currículos e uma indicação de formação mais humanista do "operador do Direito" a fim de aproximá-lo da realidade social emergente, elaboram e comprovam a eficácia de métodos mais indicados para a apropriação de conceitos científicos na área, e, mormente denunciam entraves como a falta de possibilidade de trabalho, multi, inter ou transdisciplinar ou na gestão da educação. Todavia, elas parecem não atacar a questão das raízes epistemológicas do Direito que é produzido dentro e fora dos centros formais de educação jurídica, no seu mundo real e suas implicações no ensino, nem tampouco as questões de relação de poder e os discursos subjacentes a fim de romper com o dito ciclo. Portanto, o novo conhecimento para atender aos novos e emergentes direitos em um meio sabidamente em processo de acelerada complexificação deve ser produzido levando-se em consideração as relações mediáticas e as inter-relações entre os subsistemas envolvidos e seus elementos constitutivos. Há tempos a tal crise paradigmática da própria ciência do Direito está imbricada com a crise do ensino jurídico e muito embora esta imbricação já tenha sido diagnosticada sob várias nuances e teorizada sob diferentes referenciais teóricos, não se percebe, ainda, intervenções na práxis do ensino suficientes para uma superação destes problemas. Ainda não se consegue vislumbrar o que seria o novo a fim de atender às novas demandas sociais, embora seja pacífico que estas não têm sido atendidas a contento. Nem tampouco, noutra seara, deve-se atribuir a situação de "caos” paradigmático a culpa de toda estagnação científica para o Direito. Afinal, de acordo com Gramsci (1999, p. 189) "a crise consiste justamente no fato de que o velho morre e o novo não pode [ou não consegue] nascer”, acrescentando-se que se os novos estudos ainda não permitiram a 
transcendência do velho, ao menos, fazem parte de um corpo de produção científica capaz de diagnosticar e quiçá apontar novos caminhos.

Portanto, o novo conhecimento para atender aos novos e emergentes direitos em um meio sabidamente em processo de acelerada complexificação deve ser produzido levando-se em consideração as relações mediáticas e as inter-relações entre os subsistemas envolvidos e seus elementos constitutivos. Ou, como salienta Mascareño (2014): "Es necesaria una reorientación de la observación educativa desde la unidad hacia la diferencia, de modo tal que ella logre entender su relación com la complejidade [...]”.

Constatada a realidade sob esta perspectiva, é possível afirmar que em relação ao ensino jurídico há também uma crise evidente e que se refere à sua gênese. E trata-se de uma crise profunda que perpassa todos os seus setores, desde o ingresso do aluno na Universidade até o cotidiano profissional do egresso. Questiona-se então: se há tempos a crise do ensino jurídico foi constatada e é debatida, muito se produziu no âmbito das pesquisas pragmáticas e teóricas sobre novos métodos e novas formas de capacitação dos futuros profissionais a fim de romper com a reprodução do saber jurídico como manutenção do status quo, por que então estas propostas não chegaram a lograr êxito enquanto efetivação do novo? Parece acertada, ainda que em fase embrionária de estudo, a hipótese de que, antes de qualquer coisa, o próprio estudo dos complexos envolvidos não é realizado sob uma base epistemológica e metodológica mais apropriada para a solução destes impasses. E mais, o próprio objeto de investigação parece não condizer com as perguntas que devem ser feitas. $\mathrm{O}$ que permite considerar que muitas pesquisas e propostas delas resultantes não adentram no cerne da origem da crise e destacam apenas possibilidades de combate às consequências. Ademais, parecem eivadas as tentativas de transformação social ou melhor adequação das repostas do Direito à sociedade focando tão somente a função do subsistema Educação Jurídica.

Dessa forma e considerando a crise paradigmática da Ciência Jurídica como um pressuposto já diagnosticado da própria crise do Direito, é factível afirmar que os meios de reprodução do saber jurídico passam pelos profissionais que no ensino atuam e que, mormente, nem se percebem na dita crise. A educação jurídica tradicional, que se conforma e não questiona a "redução legalista do conhecimento jurídico", que vê o Estado como a única fonte do Direito e a norma estatal como "único objeto legítimo da juridicidade", bem como reproduz constantemente as decisões proferidas nos Tribunais, retira do acadêmico essa possibilidade de reflexão e reduz suas habilidades jurídicas a procedimentos formais e condicionados às questões legalistas sem questionar a própria existência das normas no seu contexto histórico. (AGUIAR, 2004). Não conseguem ou não podem vislumbrar a sua função sócio-político-jurídica.

Nesse sentido, a mudança de paradigma para enfrentamento das questões jurídicas contemporâneas se torna essencial na medida em que, para uma sociedade de relações complexas, a simplicidade e a 
instrumentalidade com as quais se lidam com os problemas, não são suficientes. Bodnar e Cruz (2011, p. 78, grifado) ressaltam que em se tratando da ciência jurídica o paradigma deve ser entendido como "[...] o critério de racionalidade epistemológica reflexiva que predomina, informa, orienta e direciona a resolução dos problemas, desafios, conflitos e o próprio funcionamento da sociedade." Alternando-se os objetos ou seu contexto e sendo insuficientes as formas de estudá-los é salutar a adequação dos métodos de compreendê-los. Assim, a proposta da teoria dos sistemas de Luhmann tem “[...] proporcionado a configuração de um novo 'estilo científico' mais apto à compreensão das atuais sociedades complexas que vivemos, estando no centro das discussões atuais sobre o sentido do direito e da sociedade". (ROCHA, 2005, p. 33).

Ademais, para Guerra Filho (2001) as investigações jurídicas devem levar em conta o momento no qual se encontra a ciência, que deve ser de transformação produtora e não de reprodução metódica. E, portanto, a discussão no que se refere ao método mais apropriado é imprescindível. Além disto, é preciso considerar que ao se tratar da Ciência do Direito, automaticamente se estará tratando do próprio Direito, porquanto toda metodologia do Direito está fundamentada nalguma Teoria do Direito ou tende a implicá-la.

Portanto, ainda que sumariamente, o que se percebe é a interdependência investigativa entre o Direito, a Ciência Jurídica e a sua forma de ensino: A Educação Jurídica. Todavia, no caso desta, considerando seu locus nas Instituições de Ensino Superior, a sua função parece evidente, mas analisando-a sob os pressupostos da teoria sistêmica, revelam-se questões ainda obnubiladas. O sistema educativo é sim, como os demais sistemas parciais da sociedade, dotado de diferenciação funcional com código de identificação e programa específico. Para Luhmann e Schorr (1990, p.57):

[...] el sistema educativo se diferencia de otros sistemas funcionales por la forma en que aplica sus próprios programas a la hora de repartir mejores o peores posiciones.[...] la selección resulta inevitable por la creciente diferenciación funcional del sistema social.

Assim, o código dos sistemas educativos dá-se na distinção melhor/pior, que reflete e é a seleção social futura do aluno. Mas o código "classifica" por meio de programas que orientam as ações e decisões do sistema. Os programas podem alterar, mas o código de classificação não. Dessa forma, a função da educação ficaria adstrita à seleção social. Ou seja, a inclusão social do sujeito no sentido de carreira. ${ }^{4}$ Não interessa por ora, o papel da pedagogia neste sistema, mas a Educação enquanto sistema, posto que o foco de estudo são as interferências possíveis entre os sistemas parciais já citados. Ademais, como salientou César (1999, p. 72, grifado):

[...] el sistema educativo aparece como uno más de los sistemas funcionales de la sociedad, que se conserva en un entorno complejo e altamente contigente; a pesar de su papel central como agente orientada a la reproducción del mundo simbólico de la vida social no puede reclamar para sí ningún tipo de prioridad sistémica. Es como se el sistema si viera forzado a

\footnotetext{
4 "El término carrera se toma aquí en un sentido del todo general, sin referencia a posiciones y sueldos dentro de una organización. En él se incluyen, como elementos, sucesos que hacen variar la posición y que han ocurrido por elección propia del individuo o por selección venida del exterior. Carrera no es nunca, por tanto, sólo el mérito propio o sólo destino, sino un producto de ambos." (LUHMANN; SCHORR, 1990, p. 57).
} 
aceptar un papel humilde: se ve compelido a colaborar com otros sistemas (prestaciones), y a realizar intercâmbios com éstos.

Aliás, Luhmann (1990) ressalta que é esta uma das grandes vantagens da educação. A possibilidade de obter resultados que sirvam para outros sistemas. Apesar de considerar a existência de um subsistema educativo, a educação não possui um fim em si mesma, mas um pressuposto de cooperação entre os outros sistemas. Justamente porque ela tem se voltado para as carreiras profissionais é que acaba havendo um nexo entre o objeto da educação, a escolha de seus conteúdos e a possibilidade de transferir os seus resultados.

Y cuanto más compleja se haga la sociedad y más móvil la participación de los individuos en una pluralidad de sistemas sociales, tanto más inevitable es también la diferenciación externa de un sistema educativo que prepare a los individuos para vivir fuera del mismo. (LUHMANN, 1998a, p. 251)

No mesmo sentido, Schwartz (2009, p. 142) assevera que:

[...] se o sistema educativo [...] também faz parte do sistema social, ele exterioriza, a partir de sua própria funcionalidade, comunicações que vão ser refletidas no entorno dos demais sistemas, sendo por eles amealhadas e reprocessadas de forma recursiva.

Assim, ficaria evidenciada de um lado a função da educação na sociedade complexa, mas de outro, a escolha dos temas a serem exigidos como meta dentro do código melhor/pior no que se refere à educação jurídica, sempre partirá do sistema jurídico posto. De qualquer forma, antes de se vislumbrar a possibilidade de interferências intersistêmicas com vistas a uma resposta mais adequada do Direito, cumpre destacar que o ciclo de reprodução do conhecimento dantes descrito, percorre todos os subsistemas em análise. O "judiciário" por meio de seus "operadores" ou decidem com base no que já fora decidido, ou com base no que é produzido pela doutrina. Mas o que é produzido pela doutrina também é replicado na academia, que forma novos "operadores" exímios replicadores. Enfim, a Ciência Jurídica e o Direito são reduzidos e simplificados ao ponto de serem facilmente reproduzidos sejam por meio de publicações científicas ou não, seja por meio de decisões concretas. E o locus acadêmico apropriado, qual seja, as Universidades, tem sucumbido a essa reprodução. Mesmo comportando exceções, essa é a realidade de reprodução que condiciona todos os sistemas parciais em foco. Tal reformulação é vista como alternativa para uma adequação necessária do sistema jurídico e conclui-se que:

[...] os mecanismos intersistêmicos da observação e da interferência estabelecidos entre o subsistema jurídico e os demais subsistemas tenderão a produzir efeitos regulatórios mais eficientes a partir da incorporação de um maior grau de reflexividade ao direito. Dessa forma, a reflexão jurídica tomará em conta o fato de que o direito constitui um subsistema autopoiético de segundo grau diferenciado funcionalmente e que interage limitadamente com outros subsistemas autopoiéticos de segundo grau diferenciados funcionalmente. Com isso, a doutrina jurídica poderia auxiliar na formulação dos modelos de interação intersistêmicas mais apropriados e na promoção dos ajustes necessários à otimização da regulação social pelo direito. (ZYMLER, 2002, p. 188, grifado).

Como isso não é absolutamente nenhuma novidade é preciso enfrentar, pelo menos ao nível teórico propositivo ou de denúncia, definitivamente quais são as possibilidades reais e de que forma os sistemas da Ciência e da Educação podem, em abertura cognitiva com o meio, interferir adequadamente no sistema jurídico. 
Deixando de lado qualquer ingenuidade investigativa, é sabido que o número de variáveis intervenientes é grande. Mas a indústria da reprodução científica é tão evidente que já se tornou objeto de vários estudos. Dentre eles é possível citar tese de Kunz (2011) que avalia exatamente a dinâmica de produção de conhecimento na área do Direito no Brasil. No mesmo viés, a própria política de Estado e o papel do $\mathrm{CNPq}$ já foram avaliados enquanto indutores na produção científica (KATO, 2012).

Essa possibilidade de interferência na Ciência, nunca foi descartada por Luhmann. É a possibilidade de outros sistemas interferirem na concretização das operações deste sistema. Para Luhmann (1996, p.211), as comunicações que se revelam como sendo verdadeiras ou falsas e por consequência a capacidade de aplicação posterior é que são as operações do Sistema da Ciência. Ressalta-se que é possível que ocorra uma intervenção no financiamento externo do sistema para as pesquisas, que a política interfira na liberdade de expressão do pesquisador e que isso acarrete uma alteração direta na investigação em andamento podendo até mesmo levá-la ao encerramento. Da mesma forma, pode ocorrer que os participantes das pesquisas por livre vontade desistam deste trabalho, ou que o tempo destinado para pesquisa seja remanejado para a docência. Igualmente, a opinião pública ou o fato de uma temática estar em voga pode direcionar sobre o que as pesquisas devem eleger como objeto de investigação. Tudo isso pode afetar os resultados do sistema da ciência, corroborando para seu êxito ou não. Mas, de fato, ainda que certamente outros sistemas funcionais possam interferir na ciência enquanto operam suas próprias funções, eles não conseguem e não podem, por meio de seus códigos, predicar o que é verdadeiro ou falso, sob pena de exercerem uma corrupção sistêmica. Com interferência de outro sistema ou não, a autonomia da ciência está garantida, não afetando a validade de sua comunicação. No entanto, Luhmann (1996, p. 212) ressalta que essas influências externas, ainda que não afetem a autonomia do sistema da Ciência, interferem no grau de diferenciação funcional e consequentemente no grau de complexidade que ele pode chegar, posto que, se uma determinada investigação é proibida ou não financiada, o desenvolvimento da teoria a respeito restará prejudicada.

Por outro lado, há que se atentar para a função do Sistema da Ciência e as formas de legitimação de suas comunicações, posto que também podem influenciar sobre o que comunica. Ora, a Ciência é um sistema de diferenciação do sistema global da sociedade "[...] que opera com base em el medio de comunicación verdad. Em relación com la sociedad global, la ciência desarrolla la función de construir y obtener conocimiento." (CORSI; ESPOSITO; BARALDI, 1996, p. 38). A partir de seu código verdadeiro e não verdadeiro gera-se uma expectativa de que, a partir deste sistema, seja possível confiar nas comunicações emitidas por ele. Porém, quando se verifica que este sistema permite uma constante reprodução de conhecimento muitas vezes sem acrescentar nenhuma novidade, tem-se que sua credibilidade pode abalar-se. Numa sociedade em constante complexificação na qual o tempo se relativiza e há urgência para obter as informações corretas, há que confiar em mecanismos de certificação 
sobre as informações e sobre os acontecimentos. Para Luhmann (1996, p. 177) é necessário, assim, que exista um símbolo que abrevie o acesso aos acontecimentos de forma mais segura. Por isso, ele apresenta a figura do observador sobrecarregado, a partir do qual é possível verificar quem efetivamente é a autoridade responsável pela emissão da verdade. Essa orientação abreviada diz respeito à reputação para tal operação, que por sua vez gera crédito. "Por ló mismo, el sistema tiene que poner a disposición modelos para reducir la arbitrariedad de selección de temas, de la lectura, de las citas, y de las formulaciones, y precisamente eso sucede em la ciência mediante el establecimiento de la reputación." (LUHMANN, 1996, p. 177). Essa reputação se dá primeiramente aos autores, ou seja, para as pessoas. Todavia, esse grau de confiabilidade também é dado a certas organizações como universidades, centros de pesquisas e outros. Isso enaltece o lado positivo, do ponto de vista da garantia e chancela da comunicação, e neste caso podem ser citados os órgãos de cotrole como CAPES e CNPq. Mas por outro, a reputação por si só, pode fomentar uma produção científica nem sempre inovadora.

É neste tocante que se dá a inquietação a respeito do sistema da Ciência, e, por conseguinte do subsistema da Ciência Jurídica. Pois, conforme alguns exemplos de intervenção e direcionamento das pesquisas comentados e somando-se ao índice de reprodução do conhecimento possibilitado pelo sistema de validação da comunicação científica, é possível considerar que a Ciência Jurídica não tenha logrado desenvolvimento e êxito para a solução a contento das demandas complexas contemporâneas. Ou pelo menos, que seu produto, as comunicações científicas sobre o Direito, não esteja sendo observado pelo Sistema do Direito. Logo, prospectar intervenções que modifiquem estas interferências sistêmicas no sistema da Ciência de modo que a teoria possa se desenvolver livremente e de forma mais eficaz, soa importante.

Além disso, Corsi, Esposito e Baraldi (1996, p. 38) explicam muito bem que se deve ter em mente que as estruturas do sistema da ciência são muito diferentes de outros sistemas, pois são baseadas em expectativas de nível cognitivo e, como tal, estão à espera de uma nova descoberta. Sendo assim, a estrutura é suscetível de mudança mesmo que um experimento ou uma investigação não obtenha êxito. A partir do momento que surgem novas teorias ou novos conceitos, há uma reestruturação no sentido de aceitar esse novo como parte integrante da estrutura, a partir da qual o sistema funcionará.

Em que pese Luhmann ter ido além das questões colocadas por Humberto Maturana a respeito da autopoiese dos sistemas e ter substituído a teoria do conhecimento com base no sujeito para uma centrada nas operações e comunicações (ROCHA, 2009, p. 13), é mais fácil compreender o funcionamento dos sistemas autopoiéticos com base nos diversos tipos de construtivismos referentes a diversas áreas do conhecimento como: educação, psicologia, cibernética, matemática, entre outras. Nesse sentido, um grande expoente na esfera da

\footnotetext{
${ }^{5} \mathrm{O}$ crédito científico também toma destaque no pensamento de Bourdieu (2001, p. 96). Para ele "El premio del 'crédito científico' no es dinero sino lãs recompensas garantizadas por la valoración de los colegas, reputación, prêmios, empleos, participación em sociedades. [...] Está vinculado al nombre del científico y construído como no-monetario."
} 
psicologia da educação a trabalhar o construtivismo foi Jean Piaget (biólogo, psicólogo e epistemólogo). A partir da análise sumária de como o desenvolvimento mental do sujeito ocorre é possível vislumbrar como é possível a observação e internalização de conhecimentos alheios ao interior do sistema, ou seja, a abertura cognitiva. $\mathrm{O}$ desenvolvimento cognitivo foi profundamente abordado por Piaget em uma das suas obras principais, "A Equilibração das Estruturas Cognitivas", na qual a teoria da equilibração explicita cientificamente o amplo processo da aquisição e construção dos conhecimentos.

Para Krepsky (2006) quando surge um novo fato, informação ou conhecimento (esquema) a ser adquirido, ocorre um desequilíbrio no sistema mental, que se manifesta através da necessidade de reequilibrá-lo. Esse novo esquema pode se integrar ao sistema total anterior quando os elementos exteriores se incorporam aos internos ou quando se complementam reciprocamente ocasionando assim a assimilação do novo. Quando o sistema cognitivo total estiver adaptado como o novo exterior, ocorre uma acomodação e pode-se dizer que se encontra novamente equilibrado. Esta passagem assimilação - acomodação é contínua e essencial para a manutenção do equilíbrio das estruturas cognitivas. Estas passagens são progressivas e nunca atingem um estágio final de equilíbrio, por ser infinita a construção de novas estruturas mentais. Conforme precisou Piaget (1969), toda necessidade ocasionada por um desequilíbrio, tende a fazer com que o mundo exterior se incorpore ao interior do sujeito somando-se às estruturas já construídas, ou fazendo-se um reajustamento destas em relação àquelas. Se não houver esse desequilíbrio [irritação] ao sistema cognitivo, não haverá esforço ou ação do sujeito sobre ele e nada será acrescentado à estrutura cognitiva.

Para o sujeito assimilar esse novo conhecimento, ele terá que incorporá-lo aos seus esquemas anteriores sem perdê-los, mas reestruturando-os. Quando esse novo esquema estiver incorporado, ocorrerá a satisfação à necessidade, ou seja, o equilíbrio da estrutura cognitiva. Ressalta-se, entretanto, que a categoria necessidade, aqui, não deve ser entendida como desejo (que já seria um aprimoramento dispensável da necessidade), mas como aquilo que é necessário para o esquema cognitivo do sujeito sempre crescer, evoluir, aprimorar, enfim, desenvolver. No ínterim, entre o surgimento de algo novo, a necessidade (desequilíbrio) do sujeito interligá-lo com seus conhecimentos anteriores, adaptando-os para a formação de um novo esquema geral, assimilando-o e, por fim, acomodando-se mentalmente (equilíbrio), ocorre um caminho mental complexo e que nem sempre garantirá a efetiva assimilação e incorporação do novo, podendo inclusive haver total rejeição deste conhecimento [fato, informação] $]^{6}$. (KREPSKY, 2006)

Uma das complexidades que envolvem esse processo se dá quando o novo não é automaticamente assimilado, causando então uma perturbação ao sistema cognitivo. Essa perturbação pode ser considerada como "algo que serve de obstáculo a uma assimilação, tal como atingir um objetivo" (PIAGET, 1976, p. 24). Quando

\footnotetext{
${ }^{6}$ Considerado por Piaget uma regulação por "feedback" negativo.
} 
uma perturbação se manifesta, ocorrerá uma resposta a ela, através de uma regulação cognitiva, um reajustamento, sempre tentando manter um sistema mental total harmônico, conservando-o. Podemos afirmar que as respostas para explicar o novo são automaticamente buscadas no sistema mental anterior ou atual. Quando o novo é assimilado, embora o anterior se transforme, não se descaracteriza.

Via de regra, as regulações cognitivas levam a uma forma de compensação, no intuito de eliminar a perturbação e retornar ao equilíbrio, acomodação. O que se faz importante salientar, é que será na ação do sujeito que ele encontrará as respostas para a perturbação surgida. "De modo geral, o equilíbrio das estruturas cognitivas deve ser concebido como compensação das perturbações exteriores por meio das atividades do sujeito, que serão as respostas a essas perturbações." (PIAGET, 1969, p. 104). É por esse motivo que o fazer, o agir sobre e com o conhecimento se faz necessário na concepção de Piaget.

Essas explicações transportadas para o funcionamento dos sistemas mostram muito bem que os sistemas podem aprender, mas sob que circunstâncias e, sobretudo, demonstram que "[...] el conocimiento no se basa em su correspondência com la realidad externa, sino siempre únicamente sobre los construcciones de um observador." (CORSI; ESPOSITO; BARALDI, 1996, p. 51). E isso não implica de modo algum em ruptura com o código do sistema. Pelo contrário, pois como explicam Corsi, Esposito e Baraldi (1996, p. 38), ele mesmo estimula que, a partir dos erros, novos experimentos ocorram para que a evolução do sistema se dê com êxito. Isso chama a atenção, em especial porque a teoria ao explicar a autopoiese dos sistemas, demonstra que o novo sempre sofre resistência, a exemplo do sistema do Direito. O fato de que se cometa um delito, desviando-se assim da expectativa comportamental, não permite que isso se torne normal ou incorporado às estruturas do Direito. Nem mesmo se isso ocorrer com muita frequência. Simplesmente, porque isso continuará sendo ilícito e o código fará a seleção de normalidade do sistema. Em contrapartida, no sistema da Ciência, o tratamento do desvio é exatamente oposto, pois cada comunicação científica produz [ou deveria produzir] uma novidade que passará a servir [ou pelo menos deveria servir] de parâmetro para a comunicação futura se obtiver êxito ou for considerada verdade. Mas essa comunicação também pode ser abandonada porque restou caracterizada como "[...] no verdadera o como carente de conexiones relevantes para la investigación. De qualquer modo hay sentido em la producción de la investigación sólo si se llega a tener algo nuevo que decir". (CORSI; ESPOSITO; BARALDI, 1996, p. 38, grifado). E esse é ponto nodal de toda a problemática aqui exposta, visto que se o sistema da Ciência (e do subsistema dela, a Ciência Jurídica) tem permitido uma reprodução do conhecimento, obstaculizando a assim sua evolução, torna-se ainda mais difícil pensar na efetividade da produção considerada científico-jurídica. E o problema abre outras duas frentes emblemáticas: o que não é novidade não poderia ser considerado comunicação do Sistema da Ciência e o Sistema do Direito mantém sua estrutura sem irritações advindas daquele. 
Além disso, o que se percebe, é que o sistema educativo parece corroborar com esses problemas. Ora, mesmo que o sistema educativo seja autônomo e seja considerado diferenciado funcionalmente do seu entorno, os atores que lá são determinantes (docentes) replicam no seu atuar as decisões que advém do sistema jurídico. O que vem ao encontro do já pesquisado sobre a escolha das áreas de interesse de pesquisadores diagnosticada por Kunz (2011) posto que linhas de pesquisa e escolhas das áreas objeto de estudo de vários pesquisadores são instigadas por problemas vivenciados nas suas vidas de prática profissional.

Então, se o código do sistema educativo gira em torno do melhor ou pior e para a seleção social/carreira pessoal, tem-se como consequência que ao sistema educativo jurídico resta uma função que colabora para a manutenção do sistema jurídico e do status quo social. Diante disto, o desafio centra-se então, primordialmente, em vislumbrar uma prestação tanto da Ciência Jurídica quanto da Educação Jurídica que seja suficiente para que haja uma interferência no sistema jurídico. Portanto, questiona-se: existem possibilidades de interferências suficientes advindas destes sistemas? É por isso que as expectativas são também depositadas nas Instituições de Ensino Superior, pois nelas concentram-se possibilidades de intervenções nas duas esferas, educacional e científica.

\section{RELAÇÕES INTERSISTÊMICAS POSSIVEEIS}

Não obstante a correlação demonstrada entre os sistemas parciais objeto de estudo, faz-se necessária a visualização da sua perspectiva sistêmica. De acordo com Guerra Filho (2001) a teoria sistêmica deve ter a capacidade de explicar a tudo, o que denomina de universalidade; e de teorizar a si própria, o que chama de reflexividade. Somando-se a isso, a teoria explica, ainda, aquilo que não é o sistema, que é o meio circundante ou o ambiente. Sendo assim, é esta diferença entre sistema e ambiente que faz parte do próprio sistema, de sorte que a sociedade (sistema global) se torna o ambiente dos subsistemas. A diferença entre os sistemas parciais e o sistema global e entre os diversos subsistemas reside na existência de elementos específicos que se relacionam entre si. Para manter um sistema como unidade, é necessária a chamada organização, pela qual ocorrem sempre as relações entre esses elementos indiossincráticos. Ressalte-se que, mesmo que os elementos de um sistema se alterem, as relações continuam, ou seja: pode-se alterar a estrutura do sistema, mas nunca sua organização. Esta decorre de relações específicas entre os elementos, aquela da interação dos elementos existentes. De toda sorte, para a teoria de Luhmann, estes elementos são as comunicações.

Assim, o desenvolvimento de um sistema é o desenvolvimento de sua própria estrutura e a partir de seus próprios elementos. Quaisquer interferências advindas do meio são consideradas irritaçôes. Elas até podem causar uma modificação na estrutura do subsistema, fazendo com que este se desenvolva. No entanto, a forma como esse 
desenvolvimento vai ocorrer obedecerá à lógica ou estrutura interna do subsistema. Nesse sentido, destacam-se as advertências de Teubner (1989, p. 116 - 118):

A evolução pode ser 'estimulada' mas jamais 'causada' directamente a partir do exterior, prosseguindo daí em diante uma lógica interna e própria de desenvolvimento - a lógica da autopoiesis. [...] as mudanças jurídico-legislativas não são o puro resultado dos interesses sociais que sucedem a reflectir-se de algum modo no 'écran' interno do próprio sistema jurídico. O mesmo vale para os processos de inovação da doutrina jurídica, onde as inovações científicas exteriores apenas possuem significado para o direito na medida em que sejam filtradas por 'critérios de relevância' jurídico-dogmáticos próprios.

Mesmo assim, é possível pensar-se em interferências sistêmicas que possam levar a uma modificação do subsistema jurídico. Nesse tocante Guerra Filho (2001, p. 187, grifado) chama a atenção para a correlação entre o Direito e a Ciência a qual se defende por ora, pois ambos são voltados para:

[...] o desenvolvimento de segurança e estabilidade no sistema social global, ao darem uma garantia de expectativas, realizando o que Luhmann denomina de 'dupla seletividade', por fornecerem a possibilidade de uma seleção dentre as diversas seleções possíveis do modo como se agir. [...] expectativas normativas, garantidas pelo Direito, e expectativas cognitivas, garantidas pela ciência [...] Os dois modos básicos de expectativas aqui mencionados, porém. não existem absolutamente separados um do outro [...].

Essa possibilidade de influência mútua é o que se chama de interferência. Assim, para que o subsistema do Direito assimile outros elementos ou conteúdos oriundos de outros sistemas parciais como da Ciência e da Educação, mesmo mantendo a sua diferenciação funcional em relação ao meio e aos demais sistemas parciais, é necessário o acoplamento estrutural. Para isso, os procedimentos específicos do Direito e que servem de reprodução jurídica (judiciais, administrativos, legislativos, etc.) também precisam ser desenvolvidos para que ele se adeque às novas e complexas exigências sociais. Nesse viés, a comunicação do Direito se exterioriza por meio da aplicação da sua normatividade com as decisões judiciais, pela elaboração de leis, entre outras formas; enquanto a da Ciência se dá por suas publicações e pelos resultados de pesquisas. (GUERRA FILHO, 2001). Por isso, a interferência da Ciência Jurídica no Direito passa a ser possível pelo modo re-entry, o qual pode se entender como sendo:

[...] a capacidade de cada sistema de controlar sua própria recursividade mediante a reintrodução de uma distinção através de uma diferença criada pela própria distinção sistema/meio no seu interior, sendo que o sistema opera em um dos lados dessa distinção, e [...] esse papel é amplamente desenvolvido pela doutrina, mais precisamente, pela teoria do direito. (LOPES JR. 2004, p. 23, grifado).

Assim, se tanto a produção científica como a forma de ensinar os atores do sistema jurídico a lidar com o Direito perpassam o meio acadêmico, ou seja, está mais adstrito às Instituições de Ensino Superior, resta verificar a possibilidade de interferência do Sistema da Educação Jurídica no Direito, enfim, explicar sob que condições e limitações isto pode ocorrer. Neste tocante, indispensável o aprofundamento do conceito de interferência intersistêmica trabalhado por Günther Teubner, acrescido da compreensão e distinção do que é o acoplamento 
estrutural de sistemas. Para Zimler (2002, p. 175) a interferência intersistêmica ocorre "quando dois subsistemas partilham o mesmo evento comunicativo". Assim,

O mecanismo da interferência funciona como uma espécie de ponte entre os subsistemas sociais, graças ao qual estes não apenas ultrapassam os horizontes da mera auto-observação, como se articulam reciprocamente num mesmo e comum evento comunicativo. (TEUBNER, 1989, p. 173)

Os sistemas podem e devem se relacionar com o meio e com outros sistemas, a partir de elementos contidos num ou noutros até mesmo para manterem-se existentes. Para King (2009, p. 86),

Tão logo se estabeleça essa relação entre o Direito e eventos em outros sistemas, o caminho está aberto para que a relação continue e para futuros eventos no mundo social de natureza semelhante automaticamente causem o aparecimento de coisas semelhantes dentro do sistema jurídico. Na linguagem da teoria autopoiética, uma perturbação no ambiente social que penetre o sistema de sentidos do direito cria um acoplamento estrutural.

Isso, todavia, não quer dizer que o sistema deixa de existir em sua clausura operativa e tampouco que exista comunicação direta. Ressalta-se que suas operações só serão realizadas com base na própria estrutura do sistema. Entretanto, os elementos existentes no meio ou noutro sistema, constituir-se-ão em auxílio para o sistema operar, sem, contudo, alterar o seu código. Ademais, mediante uma seleção prévia, o sistema só irá operar ou reagir a esses estímulos se ele conseguir processar esse elemento ou informação na sua estrutura já existente. Afinal, para Teubner (1989, p. 174)

Interferência não significa que a informação seja carreada entre os sistemas através de uma relação directa input-output. A informação é sempre gerada ab novo em cada subsistema social, só que, no contexto da interferência com a particularidade de ser gerada simultaneamente e na base do mesmo evento comunicativo no seio dos sistemas em causa.

Além disso, as pessoas individualmente, como sistemas psíquicos que são, não podem, por si só, modificar os sistemas aos quais pertencem. Não podem, por exemplo, produzir normas jurídicas. Nesse sentido King (2009) ressalta que a realidade dos juristas, como advogados, difere da realidade do sistema jurídico, mas declara que as perturbações que eles podem causar no ambiente social é que permitem que ocorram acoplamentos estruturais entre o sistema jurídico e outros sistemas sociais. Denota-se assim, que as limitações são muitas. Isto propicia a manutenção do sistema como autônomo, auto-referente, enfim autopoiético. Porém, não quer dizer, como já fora assinalado, que o subsistema jurídico existe em condição de isolamento de outros subsistemas. É por isso que os conceitos de autonomia e autarquia foram esclarecidos por Luhmann (1980, p. 61):

O conceito de autarquia aplica-se diretamente aos processos de permuta (intercâmbio) entre sistema e meio ambiente. Um sistema é autárquico (ou independente) [...] na medida em que se pode tornar independente do meio ambiente e existir por conta própria. $\mathrm{O}$ conceito de autonomia aplica-se, em contrapartida, à orientação destes processos de intercâmbio, através de estruturas e métodos próprios do sistema, portanto parte logo do princípio de que o sistema não é independente. 
Esta dependência do meio e de outros sistemas ocorre com restrições e por meio do que Luhmann (2010, p. 139) chama de irritação (perturbação, estimulação) que significa “[...] desenvolver o processamento de informação que só pode realizar dentro do sistema”. Sendo assim, Luhmann (2010, p. 279) acrescenta que:

Os acoplamentos estruturais não produzem operações, mas somente irritações (surpresas, decepções, perturbações) no sistema. Devido ao contexto de operação do sistema, tais irritações podem servir para que o próprio sistema reproduza as operações seguintes [ou seja, manter a sua autopoiese].

Todavia, se é difícil causar irritações ao Sistema do Direito por meio dos Sistemas da Ciência e da Educação pelos motivos já comentados, por outro lado é factível prospectar que algumas absorções do novo possam se dar no campo das decisões das organizações. Nesse sentido, os Tribunais abarcam uma tarefa de se por em abertura com o entorno. Precisam observar não só a própria estrutura do Direito, mas também o meio ambiente, mesmo assumindo o risco. Luhmann (2005a, p. 63) salienta que é no âmbito dos sistemas sociais mais organizados que a demonstração de que a abertura se permite pela clausura é evidente. Isso porque a permanência da necessidade de decisões que se dá através de decisões, permite que o sistema se coloque numa situação de intranquilidade produzida por ele mesmo. Ou seja, é uma irritabilidade endógena. Pois, como elucidam Rocha e Azevedo (2012, p. 207), o fechamento operacional só é reconhecido "[...] sobre a base de decisões próprias pelo fato de que toda decisão deve ser aceita como premissa de decisões posteriores, e, dessa forma, [...] contribuir para com a absorção de incertezas." E esse processo de tomada de decisões exige que o sistema esteja sempre abastecido de informações. Portanto, ele se coloca em abertura, disposto a estímulos externos. Logo, conforme salienta Luhmann (2005b, p. 233), para os Tribunais revisarem as decisões judiciárias vislumbra-se uma observação de segunda ordem que, neste caso, é a:

[...] observación de decisiones jurídicas (leyes, contratos, decisiones judiciales) que, a su vez, han ya observado el derecho. El término técnico se llama: interpretación. Por cierto también em las reflexiones sobre la creación de la ley y los contratos la interpretación del derecho vigente juega un papel, pero sólo para circunscribir los límites del espacio creativo. Los tribunales interpretan en un sentido diferente, a saber, de manera argumentativa: para demostrar la racionalidad de su propia decisión. Aquí la observación de segundo orden se utiliza para examinar hasta dónde la consistencia de la observación del derecho obtenida hasta la fecha deja integrar nuevas informaciones o cambios en las preferencias.

Diante de tal possibilidade de mudança estrutural, ressalta-se, novamente, o equivocado papel da produção jurídica, pois, como bem salientou Luhmann (2005b, p. 233): "si la doctrina e investigación académica se interesan por 'las ciencias del derecho', lo hacen en el sentido de la reconstrucción de las decisiones correctas que han tomado los tribunales."

\section{CONSIDERAÇÕES FINAIS}

As inter-relações entre os subsistemas Direito, Educação e Ciência mostram-se como possibilidade de uma efetiva transformação social, porém são inúmeras as limitações. Isto porque existe uma auto-reprodução 
inerente a cada um deles, e que, mais do que mantê-los adaptado ao meio circundante e em funcionamento, ela também pode revelar um caráter limitador de modificações importantes. Entretanto, o que se mostra conclusivo é que, a partir de uma melhor compreensão sobre a prestação dos subsistemas Educação e Ciência a partir da ótica do subsistema jurídico, é possível vislumbrar uma melhor adequação da função do Direito e, por consequência, uma melhor correspondência às expectativas da sociedade.

Isso não quer dizer que uma análise apenas no âmbito da auto-observação individual destes subsistemas deva ser desconsiderada. Nem tampouco que as produções científicas sob essa formatação e reconhecidas no meio acadêmico não surtam efeitos práticos e representem uma devolução à sociedade atendendo aos fins sociais da pesquisa. O que se vislumbra por meio desta investigação teórica é que o estudo dos conhecimentos produzidos nas esferas jurídica, científica e educacional e das interferências entre os subsistemas sociais indicados e que supostamente partilham de eventos comunicativos, pode possibilitar um salto qualitativo metodológico até mesmo para outros objetos de investigação mais específicos na esfera jurídica.

Assim, se o diagnóstico atual indica que todos os subsistemas sob comento precisam adequar-se e que suas limitações individualizadas são muitas, mas ao mesmo tempo ressalta as suas interdependências, o que se mostra desvelado, por ora, é o enfrentamento de quais são os limites e possibilidades das interferências intersistêmicas entre os subsistemas Direito, Educação e Ciência e qual é a prestação dos dois últimos para que a função do Direito possa atender as demandas desta sociedade complexa com a efetivação dos novos direitos. Ademais, como diagnóstico e recomendação, eis que o campo teorético de Luhmann ainda se encontra em fase de exploração científico-acadêmica, faz-se necessário olhar para o fenômeno apresentado neste trabalho despido de ingenuidade metodológica. Prospectar uma possível intervenção consistente nos subsistemas da Educação e da Ciência de modo a produzir efeitos no Sistema Jurídico prescinde de uma observação dos problemas em sua complexidade com a qual um aparato de cunho pragmático-sistêmico se mostra apropriado.

A observação do fenômeno sob a luz desta matriz teórica permite perceber que há limitações nas interferências. Isto porque, embora o subsistema jurídico seja aberto cognitivamente e os elementos comunicativos dos subsistemas Ciência Jurídica e Educação Jurídica possam ser alterados por meio da interação indireta com o meio, esta alteração pode ser aceita ou não pelo subsistema jurídico que recebe a prestação. Além disso, essa recepção pode ser parcial ou apenas para acomodação ao subsistema preceptor resultando na autoreprodução deste mediante seus códigos já estabelecidos. Porém, interações construtivas e modificativas do subsistema Jurídico de forma a atender com maior propriedade as demandas sociais podem ser possíveis a partir da possibilidade da comunicação das organizações, ou seja, no âmbito de suas decisões. Se não isso, pelo menos, por meio do processamento pelo Direito de eventos específicos dos subsistemas Educação e Ciência constituindo 
ruídos eficazes para uma efetiva produção de conhecimento capaz de possibilitar uma adequação das respostas do Direito para as demandas da sociedade em progressiva complexificação.

\title{
LAW, SCIENCE AND EDUCATION: INTERSYSTEM RELATIONSHIPS ${ }^{7}$
}

\begin{abstract}
This article advances a theoretical approach to the necessity of becoming aware of systematic relationships between Law, Education and Science as a possibility of overcoming the reproduction of knowledge in order to enable the law system to offer more suitable answers to the rights that emerge in this complex and organized society. Under the light of Niklas Luhmann's pragmatic-systemic theory and its contemporary re-readings, limits are pointed and possibilities of intersystem interferences of the Education and Law Science in the Legal system, since all those are operationally-closed systems, but cognitively open. Conclusions are that, due to autopoiesis, it is not possible to directly transpose scientific legal production, nor even of knowledge built at Universities, to the legal system, so posing obstacles to significant changes in the system. It points out anyway that more significant changes to fit new social demands to the system may become more feasible by means of the identification of communication events able to introduce effective noise in the Law System.
\end{abstract}

Keywords: Law System; Science and Education; Intersystem relations; Complex Society; (Re)production of knowledge.

\section{REFERENCIAS}

AGUIAR, Roberto Armando Ramos de. Habilidades: ensino jurídico e contemporaneidade. Rio de Janeiro: DP\&A, 2004.

BERTALANFFY, Ludwig Von. Teoria geral dos sistemas: Fundamentos, desenvolvimento e aplicações. Tradução de Francisco M. Guimarães. 6.ed. Petrópolis: Vozes, 2012.

BODNAR, Zenildo; CRUZ, Paulo Márcio. "O novo paradigma do direito na pós-modernidade". Revista de Estudos Constitucionais, Hermenêutica e Teoria do Direito (RECHTD). São Leopoldo, v.3, n. 1, p. 75-83, jan. jun. $2011 . \quad$ Disponível em: <http://www.unisinos.br/_diversos/revistas/ojs/index.php/RECHTD/article/view/777>. Acesso em: 28 dez. 2015.

BOURDIEU, Pierre. El ofício de cientifico: Ciencia de la ciencia y reflexividad. Tradución de Joaquín Jordá. Barcelona: Editorial Angrama, 2001.

${ }^{7}$ Publicação com auxílio do Edital CAPES nº 002/2013 - DINTER UNISINOS/FURB. 
CÉSAR, Javier Brown. "Comunicación y política educativa." Revista Latinoamericana de Estudios Educativos. México, v.29, n. 3, p. 63-131, 1999. Disponível em: < http://redalyc.uaemex.mx/pdf/270/27029403.pdf> Acesso em: 03 jan. 2016.

CORSI, Giancarlo; ESPOSITO, Elena; BARALDI, Claudio. Glosario sobre La teoria Social de Niklas Luhmann. México: Anthropos, 1996.

DURAN, Angela Aparecida da Cruz. Que educação os advogados devem ter? ANUÁRIO DA ABEDi, Florianópolis, Fundação Boiteux, Ano 3, n.3, Boiteux, Ano 3, p. 201 - 211, 2005.

GERRA FILHO, Willis Santiago. Autopoiese do direito na sociedade pós-moderna: introdução a uma teoria social sistêmica. Porto Alegre: Livraria do Advogado, 1997.

Teoria da ciência jurídica. São Paulo: Saraiva, 2001.

GRAMSCI, Antonio. Cadernos do Cárcere. vol. 3. Rio de Janeiro: Civilização Brasileira, 1999.

KATO, Fabíola Grello. "Por um novo paradigma científico? Políticas de Estado e financiamento de pesquisas." Revista de Educação Unisinos. São Leopoldo, v.16, n.2, p. 169-178, 2012. Disponível em: < http://www.unisinos.br/revistas/index.php/educacao/article/view/edu.2012.162.09/972> Acesso em: 23 nov. 2015.

KING, Michael. A verdade sobre a autopoiese no direito. In.: ROCHA, Leonel Severo; KING, Michael; SCHWARTZ, Germano. A verdade sobre a autopoiese no direito. Porto Alegre: Livraria do Advogado, 2009.

KREPSKY, Giselle Marie. Como o aluno aprende? A importância da ação reflexiva na construção do conhecimento. Revista Jurídica, Blumenau, ano 10, n. 19, p. 217 - 230, jan-jun 2006.

KUNZ, Ivanir. Dinâmica de produção de conhecimento na área de direito no Brasil. 2011. 245 f. Tese (Doutorado em Política Científica e Tecnológica) - Programa de pós-graduação em Geociências, Universidade Estadual de Campinas, Campinas, 2011.

LOPES JR. Dalmir. Introdução. In.: ARNAUD, André-Jean; LOPES JR., Dalmir. (Org.) Niklas Luhmann: do sistema social à sociologia jurídica. Rio de Janeiro, Lumen Juris, 2004. p.1-30.

LUHMANN, Niklas. Sociologia do direito I. Tradução de Gustavo Bayer. Rio de Janeiro: Tempo Brasileiro, 1983.

SCHORR, Karl Eberhard. "Presupuestos estructurales de uma pedagogia reformista. Analisis sociológicos de la pedagogia moderna." In.: Revista de Educación. Madrid, n.29, p. 55-79, 1990.

La Ciencia de la Sociedad. México: Anthropos, 1996.

Complejidad y modernidad: de la unidad a la diferencia. Madrid: Editorial Trotta, 1998a. Disponível em:< http://archivosociologico.files.wordpress.com/2010/07/complejidad-y-modernidad-de-la-unidad-a-ladiferencia-niklas-luhmann.pdf $>$. Acesso em: 25 fev. 2016.

Sistemas Sociales: Lineamentos para uma teoría general. México: Anthropos, 1998b.

Organización y decisión: Autopoiesis, acción y entendimiento comunicativo.Trad. Darío Rodríguez Mansilla. México: Iberoamericana, 2005a.

El derecho de la sociedad. Trad. Javier Tores nafarrate, México: Iberoamericana, 2005b.

LUHMANN, Niklas. La sociedad de la Sociedad. Trad. Javier Nafarrate. México: Herder, 2007. 
Introdução à teoria dos sistemas. Tradução de Ana Cristina Arantes Nasser. 2.ed. Petrópolis: Vozes, 2010.

MARQUES NETO, Agostinho Ramalho. A ciência do Direito: conceito, objeto, método. Rio de Janeiro: Forense, 1982.

MASCAREÑO, Aldo. Diferenciación y contingencia em América Latina. Santiago: Ed. Universidad Alberto Hurtado, 2010.

MORAES, Maria Célia Marcondes de. "Indagações sobre o conhecimento no campo da educação." Perspectiva: Dossiê - Ontologia crítica e conhecimento em Educação, Florianópolis, UFSC, v.27, n.2, p. 315-346, 2009. Disponível em: < http://www.periodicos.ufsc.br/index.php/perspectiva/article/view/15727/pdf_1>. Acesso em: 5 nov. 2015.

PEREIRA, Agostinho O. K; SIMIONI, Rafael Lazzarotto. "A especificidade dos novos direitos na multiplicidade de suas referências." Revista Sequência, Florianópolis, v. 29, n. 56, p. 225-244, jun. 2008. Disponível em: <http://periodicos.ufsc.br/index.php/sequencia/article/view/14997/13679>. Acesso em: 18 dez. 2015.

PIAGET, Jean. Seis estudos de psicologia. Tradução de Maria Alice M. D'Amorim e Paulo Sérgio L. Silva. Rio de Janeiro: Forense, 1969.

PIAGET, Jean. A equilibração das estruturas cognitivas: o problema central do desenvolvimento. Tradução de Marion Merlone dos Santos Pen. Rio de Janeiro: Zahar Editores, 1976.

ROCHA, Leonel Severo. Da epistemologia jurídica normativista ao construtivismo sistêmico. In.: ROCHA, Leonel Severo; SCHWARTZ, Germano; CLAM, Jean. Introdução à teoria do sistema autopoiético do direito. Porto Alegre: Livraria do Advogado, 2005, p. 9-47.

Observações sobre a observação Luhmanniana. In.: ROCHA, Leonel Severo; SCHWARTZ, Germano; $\overline{\mathrm{KING}}$ Michael. A verdade sobre a autopoiese no direito. Porto Alegre: Livraria do Advogado, 2009, p. 11 - 40.

; AZEVEDO, Guilherme de. "Notas para uma teoria da organização da decisão jurídica autopoiética."

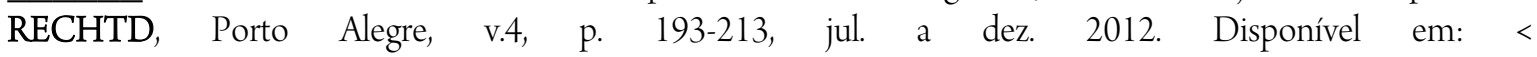
http://revistas.unisinos.br/index.php/RECHTD/article/view/rechtd.2012.42.09> Acesso em: 15 jun. 2016.

SCHWARTZ, Germano. A fase pré-autopoiética do sistemismo Luhmanniano. In.: ROCHA, Leonel Severo; SCHWARTZ, Germano; CLAM, Jean. Introdução à teoria do sistema autopoiético do direito. Porto Alegre: Livraria do Advogado, 2005, p. 51- 85.

Autopoiese e direito: auto-observações e observações de segundo grau. In.: ROCHA, Leonel Severo; KING, Michael; SCHWARTZ, Germano. A verdade sobre a autopoiese no direito. Porto Alegre: Livraria do Advogado, 2009.

SILVA, Artur Stamford. Teoria reflexiva da decisão jurídica: observações a partir da teoria dos sistemas que observam. In.: SCHWARTZ, Germano (Org.). Juridicização das esferas sociais e fragmentação do direito na sociedade contemporânea. Porto Alegre: Livraria do Advogado, 2012, p. 29 - 58.

TEUBNER, Gunther. O direito como sistema autopoiético. Tradução de José Engrácia Antunes. Lisboa: Fundação Calouste Gulbenkian, 1989.

As múltiplas alienações do direito: sobre a mais-valia social do décimo segundo camelo. In.: Niklas Luhmann: do sistema social à sociologia jurídica. Rio de Janeiro, Lumen Juris, 2004.p. 109- 143. 
ZYMLER, Benjamin. Política e direito: uma visão autopoiética. Curitiba: Juruá, 2002.

Trabalho enviado em 15 de setembro de 2016.

Aceito em 16 de abril de 2017. 